\title{
The Prevalence of Eosinophilic Esophagitis in the United States
}

\author{
Evan S. Dellon, MD MPH ${ }^{1,2}$, Elizabeth T. Jensen, $\mathbf{M P H}^{1,3}$, Christopher F. Martin, $\mathbf{M P H}^{2}$, \\ Nicholas J. Shaheen, MD MPH ${ }^{1,2}$, and Michael D. Kappelman, MD MPH ${ }^{2,4}$ \\ ${ }^{1}$ Center for Esophageal Diseases and Swallowing, Division of Gastroenterology and Hepatology, \\ Department of Medicine, University of North Carolina School of Medicine, Chapel Hill, NC
}

${ }^{2}$ Center for Gastrointestinal Biology and Disease, Division of Gastroenterology and Hepatology, Department of Medicine, University of North Carolina School of Medicine, Chapel Hill, NC

${ }^{3}$ Department of Epidemiology, Gillings School of Global Public Health, University of North Carolina, Chapel Hill, NC

${ }^{4}$ Division of Pediatric Gastroenterology and Hepatology, Department of Pediatrics, University of North Carolina School of Medicine, Chapel Hill, NC

\begin{abstract}
Background \& Aims-Eosinophilic esophagitis (EoE) has become a major cause of upper gastrointestinal morbidity in children and adults. However, there are few data on the nationwide prevalence of EoE. We aimed to estimate the prevalence of EoE in the United States (US).

Methods-We collected health insurance claims from a large database that represented the US commercially insured population. We analyzed data from 2008 through 2011, identifying cases of EoE using a previously validated definition, and calculated a period prevalence using data from 2009 through 2011. EoE was defined as any instance of the ICD-9 code 530.13. We calculated the prevalence of the code in the database and standardized the estimate to the US population.
\end{abstract}

Results-Of 35,575,388 individuals in this database, 16,405 had at least 1 code for EoE. The mean age was $33.5 \mathrm{y}, 65 \%$ were male, $55.8 \%$ had dysphagia, and $52.8 \%$ had a diagnostic code for at least 1 allergic condition. Among 11,569,217 individuals with continuous insurance coverage between mid-2009 and mid-2011, 6513 had at least one code for EoE. When standardized to the US population, the estimated period prevalence of EoE was 56.7/100,000 persons, translating to

(C) 2013 The American Gastroenterological Association. Published by Elsevier Inc. All rights reserved.

Corresponding Author: Evan S. Dellon MD, MPH CB\#7080 Bioinformatics Building 130 Mason Farm Rd. UNC-CH Chapel Hill, NC 27599-7080 Phone: (919) 966-2513 Fax: (919) 843-2508 edellon@med.unc.edu.

Publisher's Disclaimer: This is a PDF file of an unedited manuscript that has been accepted for publication. As a service to our customers we are providing this early version of the manuscript. The manuscript will undergo copyediting, typesetting, and review of the resulting proof before it is published in its final citable form. Please note that during the production process errors may be discovered which could affect the content, and all legal disclaimers that apply to the journal pertain.

Disclosures: None of the authors have competing interests related to this manuscript.

Author contributions (all authors approved the final draft):

Dellon: Project conception, study design, obtained funding, data interpretation, manuscript drafting, critical revision

Jensen: Study design, data analysis, data interpretation, manuscript drafting, critical revision

Martin: Data analysis, data interpretation, critical revision

Shaheen: Data interpretation, critical revision

Kappelman: Study design, data interpretation, critical revision, supervision

Note: The statements, findings, conclusions, views and opinions contained and expressed in this article are based in part on data obtained under license from the following IMS Health Incorporated information service: IMS LifeLink® PharMetrics Health Plan Claims Database (January, 2001 through November, 2011), IMS Health Incorporated. All Rights Reserved. The statements, findings, conclusions, views, and opinions contained and expressed herein are not necessarily those of IMS Health Incorporated or any of its affiliated or subsidiary entities. 
approximately 152,152 cases in the US. Prevalence peaked in men 35-39 y old, with a rate of $114.6 / 100,000$ persons.

Conclusions-Despite its relatively recent description, EoE is frequently diagnosed in the US, with an estimated prevalence of 56.7/100,000 persons. This estimate depends on the accuracy of the ICD-9 code, but could be an underestimate, given that knowledge of the code and recognition of EoE are increasing.

\section{Keywords}

eosinophilic esophagitis; prevalence; claims data; diagnosis

\section{Introduction}

Eosinophilic esophagitis (EoE) is a recently recognized clinicopathologic entity that has become an increasingly common cause of upper GI symptoms and morbidity in both children and adults. ${ }^{1,2}$ It is currently defined as an allergic/immune-mediated disease characterized clinically by symptoms of esophageal dysfunction and histologically by a marked eosinophilic infiltrate in the esophageal mucosa in the absence of other competing causes of esophageal eosinophilia. ${ }^{3}$ Over the last decade there has been an exponential increase in the number of publications related to EoE, but many fundamental questions about EoE remain unanswered.

While some aspects of the epidemiology of EoE are understood, ${ }^{4}$ quantifying the prevalence of EoE in the U.S. has been hampered by the lack of a central medical record system in the U.S., inconsistent application of EoE diagnostic definitions, and the difficulty of conducting population-based research at tertiary care referral centers with wide catchment areas.

Nevertheless, a number of investigators have used a variety of strategies to report prevalence estimates ranging from less than 10 to more than 80 cases per $100,000 .^{5-15}$ The potential for estimating EoE prevalence at the national level was made possible in 2008 with the approval of an International Classification of Diseases, Ninth Revision (ICD-9) code for EoE (530.13). We have recently validated this code for use in administrative database research, and found that the specificity of the code was extremely high. ${ }^{16}$ To date, however, these codes have not been used on a national level in the U.S. to study the epidemiology of EoE.

The aims of the present study were to use a large health plan claims database to identify and characterize cases of EoE, assess differences between children and adults with EoE, and to estimate the prevalence of EoE in the U.S. This is important baseline data that can subsequently be used for appreciating the burden of this emerging disease.

\section{Methods}

\section{Study design, data source, and case definition}

We performed a retrospective analysis of the IMS LifeLink® PharMetrics Health Plan Claims Database (IMS Health Inc, Waterton, MA). This database contains longitudinal, integrated, fully adjudicated medical and pharmaceutical claims for over 75 million individuals from over 80 health plans, and has been shown to be representative of a U.S. national commercially insured population. ${ }^{17,} 18$ Enrollees' demographic data including age, sex, and census region (East, South, Midwest, and West) were available.

EoE was defined as a single instance of the ICD-9 code 530.13, which was initially approved in 2008. We previously validated a single instance of this code for diagnosis of EoE using health plan claims records among commercially insured patients and reported that 
this case definition has high specificity (>99\%) balanced by a low sensitivity $(37 \%) .{ }^{16}$ Codes for GERD (530.81) and erosive esophagitis (530.11) were not used as exclusion criteria because the most recent consensus diagnostic criteria allow for the possibility for GERD and EoE to overlap, ${ }^{3}$ erosive esophagitis does not distinguish EoE from GERD, ${ }^{19}, 20$ and the ICD-9 code for esophageal reflux may be non-specific.

To characterize cases of EoE, data from 2008-2011 were analyzed in individuals ages 0-64 years who had at least 6 months of continuous health plan enrollment. In order to estimate a two-year period prevalence, account for the delay in uptake for the new code that was noted after its introduction in 2008, and allow an adequate amount of time for the code to be used, data from July 1, 2009 through June 30, 2011 were analyzed among individuals who had at least 24 months of continuous enrollment.

\section{Associated codes and conditions of interest}

In addition to the code for EoE, data on multiple other codes were extracted. These included ICD-9 codes for upper gastrointestinal (GI) symptoms, esophageal disorders, and atopic disorders (see Supplementary Table), as well as National Drug Codes (NDC) for pharmaceutical agents such as histamine-2 receptor blockers (H2RBs), proton-pump inhibitors (PPIs), corticosteroids agents that have been used topically or systemically to treat EoE such as fluticasone, budesonide, prednisone, ${ }^{21-23}$ and allergy medications.

\section{Statistical analysis}

Descriptive statistics characterized demographics, symptoms, associated diseases, and medications for subjects who met the study definition of EoE. Any patients meeting the case definition between 2008 and 2011 were included. For medication use, analyses were restricted to those patients with a pharmacy drug benefit $(n=12,390)$. Bivariate analysis was performed to assess for differences in features of children ( $<18$ years) and adults $(\geq 18$ years) with EoE using the Pearson Chi-square test.

To calculate the period prevalence, we identified all patients with continuous enrollment between July 1, 2009 and June 30, 2011. From these, we identified the number of patients who met the case definition for EoE during this period. We then divided this by the total number of patients in the database enrolled within this timeframe. In restricting our estimate to patients continuously enrolled in this period, we assured that all patients included had equal opportunity for becoming a case, should they have the disease. The overall prevalence, prevalence by sex, prevalence by census region, and prevalence by 5 -year age increments were estimated within the database. Then, the overall prevalence estimate was standardized to the U.S. population by age and sex using 2010 census data (for all individuals < 65 years of age), and the absolute number of patients with EoE in the U.S. was extrapolated from the prevalence rate.

We also performed a priori sensitivity analyses with more restrictive coding definitions of EoE. These included: 1 ) requiring one 530.13 code but excluding other conditions that could contribute to esophageal eosinophilia (see Supplementary Table); ${ }^{3} 2$ ) requiring at least two occurrences of the 530.13 codes; and 3 ) requiring at least two occurrences of the 530.13 codes as well as excluding other conditions that could contribute to esophageal eosinophilia. Because it was the most conservative approach, data for this third definition are presented for the sensitivity analysis. This study was deemed exempt from review by the UNC Institutional Review Board. 


\section{Results}

\section{Characteristics of EoE cases}

A total of 35,575,388 individuals in the database from 2008-2011 with continuous enrollment of at least 6 months represented the initial source population. Of these, 16,405 had at least one code for 530.13 and comprised the EoE case group. These patients were an average of 33.5 years old and $64.9 \%$ were male (Table 1). The mean number of 530.13 ICD-9 claims per case was 7.4 (median of 4), and the number of identified cases substantially increased between 2008 and 2009, likely indicating increasing usage of the newly introduced code in 2008.

Cases of EoE frequently had associated ICD-9 codes for esophageal symptoms and conditions including dysphagia (55.8\%), esophageal foreign bodies (12.5\%), and esophageal strictures (28.7\%) (Table 2). More than half of the EoE cases had an associated atopic disease, with rhinitis $(41.8 \%)$ and asthma (23.4\%) being most common. Approximately $10 \%$ of EoE patients had a prescription for an antihistamine and the same proportion had a prescription for a leukotriene antagonist. PPIs were also commonly prescribed, with nearly half of patients receiving a prescription for a PPI (Table 2).

Children under the age of 18 comprised $24.0 \%$ of the cases of EoE. When children were compared to adults (Table 3 ), they were less likely to have dysphagia (32.1\% vs $63.2 \%$ ), esophageal foreign bodies (6.9\% vs $12.5 \%$ ), and esophageal strictures (5.5\% vs $36.0 \%)$, and more likely to have abdominal pain ( $56.9 \%$ vs $43.7 \%)$, nausea or vomiting ( $42.7 \%$ vs $25.9 \%$ ), failure to thrive ( $11.8 \%$ vs $0.4 \%$ ), any allergic disease (65.6\% vs $48.4 \%)$, asthma $(37.7 \%$ vs $18.9 \%)$, and food allergies $(9.8 \%$ vs $3.1 \%)$ ( $p<0.001$ for all).

The distribution of demographic, symptom, and disease characteristics did not change on sensitivity analysis when the primary case definition was modified to exclude other conditions that could contribute to esophageal eosinophilia and/or to require at least two 530.13 diagnostic codes (data not shown).

\section{Prevalence of EoE}

A total of 11,569,217 individual subjects in the database from 2009-2011 with continuous enrollment of at least 24 months were used for the period prevalence calculations. In this population, there were a total of 6,513 patients with at least one code for EoE, for an overall prevalence rate of 56.3/100,000 (Table 4). The prevalence was more than twice as high in males as in females $(76.8$ vs $37.4 / 100,000)$. For both genders, the peak prevalence was in the 35-39 year age range, and there was a decreasing prevalence after age 45 (Figure 1).

When the overall prevalence was standardized to the U.S. based on age and sex, the rate was $56.7 / 100,000$, which extrapolates to 152,152 cases in the U.S. The prevalence in children ( $<20$ years) was 50.5/100,000, and in adults (20-64 years) was 58.9/100,000. After applying the more restrictive EoE case definition we found 4,515 cases of EoE in the database (Table 4), for a prevalence of $39.5 / 100,000$. When standardized to the U.S., the rate remained $39.5 / 100,000$, which extrapolates to 105,977 cases.

\section{Discussion}

Over the past decade, EoE has emerged as a major cause of upper GI morbidity in both children and adults. ${ }^{3,5-7,10,11,14,19,24,25}$ However, estimates of the prevalence of EoE in the U.S. have been limited by fragmented medical record systems and a lack of validated or consistently applied disease definitions. The aim of this study was to characterize cases of EoE and estimate the prevalence of EoE in the U.S. in a large database with methodology 
not previously possible in this field. Using a validated coding definition of EoE for detecting cases of EoE, we estimate that the prevalence of EoE in the U.S. is 56.7/100,000. We also note that the prevalence of EoE decreases after age 45, which is unexpected because for a chronic and non-fatal disease, prevalence should typically continue to increase with age. It is interesting to speculate whether this implicates an as-yet unidentified early life exposure over the past four decades as an etiologic factor.

Our prevalence estimate, obtained from a large health plan claims database and with the largest number of cases yet analyzed in the EoE literature, is on the same order of magnitude of previously reported values from smaller studies (Table 5), lending empiric validity. For example, studies in children at single centers with well-defined catchment areas have estimated the prevalence of EoE to be 43-91/100,000.5, 7, 9, 10 In adults, several studies have previously reported the prevalence to be $23-55 / 100,000.6,11,14$ A recent administrative study in a military insurance population found a lower number of cases than expected, perhaps indicating lack of uptake of the ICD-9 code for EoE or a healthier population not representative of the U.S. ${ }^{15}$ There was also a survey of adult and pediatric gastroenterologists and allergists/immunologists which estimated of the number of cases for each provider and calculated an EoE prevalence of 52/100,000. ${ }^{13}$ Because of the large numbers of both individuals and EoE cases in the database in the present study, we feel that our estimate, while of the same order of magnitude as these other studies, may be more precise. However, it is difficult to directly compare some of the prevalence values as ours is a 2 year period prevalence, and the previously reported values range from 1 year pointprevalences to cumulative prevalences representing over more than a decade of accrued cases.

To place our reported prevalence rates into context, it can be helpful to make a comparison with inflammatory bowel disease, another inflammatory condition of the GI tract. The prevalences of Crohn's disease and ulcerative colitis in a pediatric population are 43 and 28/100,000, respectively, and in adults are 201 and 238/100,000, respectively. ${ }^{18}$ Therefore, within the relatively short time frame in which EoE has been recognized as a unique disease entity, the prevalence of EoE in all subjects has approached that of pediatric inflammatory bowel disease.

A key question in interpreting the results from an administrative database study such as this is whether the case definition is accurate, and if not, what degree of misclassification may be present. One answer can be provided by examining the clinical characteristics of the identified EoE cases. We found the EoE cases to be relatively young, with a male predominance, numerous esophageal symptoms, and high rates of concomitant atopic disease. All of these features, including previously reported differences between adults and children, are expected for a population of EoE patients, 1,3, 19, 26-31 and support that we are capturing true EoE cases. Related to this, an interesting point is that frequency of esophageal perforation in this patient sample, $0.4 \%$, is essentially identical to what has been reported a meta-analysis of perforation as a complication of esophageal dilation for treatment of esophageal strictures in EoE patients. ${ }^{32}$ However, topical steroid medications were not commonly prescribed (22\% of children; $8 \%$ of adults). While one explanation for this is that these are not true EoE patients, a more likely interpretation takes into account that this study detected prevalent, not incident, cases of EoE. Whereas one would expect incident EoE cases to frequently receive a topical steroid for initial treatment, ${ }^{33}$ a prevalent case may be asymptomatic or on dietary restriction therapy so not taking a medication, or may have had a medication previously prescribed outside of the enrollment window for this study.

While it is reassuring that the clinical features of the patients identified in this study generally reflect what would be expected for EoE cases, an arguably more important 
strategy for minimizing misclassification is with validation of the case definition. Importantly, we previously validated our primary definition of EoE as at least one instance of the 530.13 ICD-9 code using administrative claims data linked to individual patient records. ${ }^{16}$ This definition was more than $99 \%$ specific using a reference standard population that met consensus diagnostic guidelines for EoE, ${ }^{1,3}$ and this level of specificity held without including an endoscopy code in the case definition. However, because this validation used administrative data from a tertiary care center, ${ }^{16}$ it is possible that specificity might have been overestimated or that sensitivity and specificity could be lower in general practice and if consensus diagnostic guidelines are not fully followed. ${ }^{34}$ It is also possible that some patients had esophageal eosinophilia due to GERD and might have been misdiagnosed with EoE, and because PPIs are available over the counter, all PPI use cannot be captured in this database. Therefore it is possible that some patients with PPI-responsive esophageal eosinophilia are misclassified as having EoE in the administrative data. To further address these possibilities of misclassification, we performed an analysis with an even more restrictive case definition of EoE. Applying this definition, the clinical characteristics were unchanged compared with the primary case definition. In addition, because almost $80 \%$ of the identified EoE cases had more than one ICD-9 claim for 530.13, with a mean number of these codes greater than 7 and a median greater than 4, we anticipate that it would be very unlikely that this frequency of diagnostic coding would represent misclassification or a coding error.

Because of the low sensitivity, it is likely that some cases of EoE have not been identified and hence the prevalences reported here may, in fact, underestimate the true prevalence in the U.S. population. First, not all individuals with EoE come to medical attention, while others may be misdiagnosed or may not have undergone diagnostic evaluation for EoE. Secondly, not all individuals diagnosed with EoE are captured by the ICD-9 code, considering its recent introduction in 2008, so there are limitations of using a new ICD-9 for a disease with an evolving definition and increasing recognition. To minimize this, we began our period prevalence estimate a full year after code introduction. Nevertheless, the sensitivity of this code may be as low as $37 \% .{ }^{16}$ This implies that the true prevalence of EoE could be as high as 153.2/100,000, which extrapolates to 411,222 cases of EoE in the U.S.

Besides misclassification, there are other potential limitations to this study that should be acknowledged. First, we are unable to present information that is not captured in administrative claims databases such as race/ethnicity, socioeconomic status, practice setting, endoscopic abnormalities, histology findings, over-the-counter medications, or indication for medication prescription (for example, was a topical steroid prescribed for asthma or EoE). We also do not have geographic data more specific than the four large census regions. Second, because the 530.13 code was newly introduced in 2008 we could not assess time trends and could not accurately estimate the incidence of the condition. Incidence calculations will be possible in planned future studies where there will be sufficient lead time without an EoE code to be confident that a diagnosis is incident, not prevalent.

These potential limitations are countered by the strengths of this study. This is a large database that has been demonstrated to be representative of all patients in the U.S. with commercial insurance. ${ }^{17,18}$ As such, it yielded the largest sample of EoE cases yet to be reported in the literature. From this, we were able to calculate prevalence rates of EoE in the database and also standardize them to the U.S. population (ages 0-64), allowing extrapolation to the total number of EoE cases in this country. 
In conclusion, this analysis of a large, nationally representative administrative database of commercially insured patients estimates that the prevalence of EoE in the U.S. is 56.7 cases/ 100,000 . While the limits on this estimate range from 39.5 to $153.2 / 100,000$, these values may still underestimate the true prevalence given that both knowledge of the new ICD-9 code and recognition of EoE are increasing. This estimated prevalence is approaching that of pediatric inflammatory bowel disease, and represents a remarkable burden of disease for a condition that has only been recognized for the past two decades.

\section{Supplementary Material}

Refer to Web version on PubMed Central for supplementary material.

\section{Acknowledgments}

Grant support: This study was funded, in part, by a University of North Carolina Junior Faculty Development Grant (ESD), and NIH Awards K23 DK090073 (ESD) and K08 DK088957 (MDK).

\section{Abbreviations}

$\begin{array}{ll}\text { EoE } & \text { eosinophilic esophagitis } \\ \text { ICD-9 } & \text { International Classification of Diseases, } 9^{\text {th }} \text { Revision } \\ \text { H2RB } & \text { histamine-2 receptor blockers } \\ \text { NDC } & \text { National Drug Codes } \\ \text { PPI } & \text { proton-pump inhibitors }\end{array}$

\section{References}

1. Furuta GT, Liacouras CA, Collins MH, Gupta SK, Justinich C, Putnam PE, Bonis P, Hassall E, Straumann A, Rothenberg ME. Eosinophilic esophagitis in children and adults: a systematic review and consensus recommendations for diagnosis and treatment. Gastroenterology. 2007; 133:134263. [PubMed: 17919504]

2. Dellon ES. Diagnosis and management of eosinophilic esophagitis. Clin Gastroenterol Hepatol. 2012; 10:1066-78. [PubMed: 22728382]

3. Liacouras CA, Furuta GT, Hirano I, Atkins D, Attwood SE, Bonis PA, Burks AW, Chehade M, Collins MH, Dellon ES, Dohil R, Falk GW, Gonsalves N, Gupta SK, Katzka DA, Lucendo AJ, Markowitz JE, Noel RJ, Odze RD, Putnam PE, Richter JE, Romero Y, Ruchelli E, Sampson HA, Schoepfer A, Shaheen NJ, Sicherer SH, Spechler S, Spergel JM, Straumann A, Wershil BK, Rothenberg ME, Aceves SS. Eosinophilic esophagitis: Updated consensus recommendations for children and adults. J Allergy Clin Immunol. 2011; 128:3-20. e6. [PubMed: 21477849]

4. Sealock RJ, Rendon G, El-Serag HB. Systematic review: the epidemiology of eosinophilic oesophagitis in adults. Aliment Pharmacol Ther. 2010; 32:712-9. [PubMed: 20662785]

5. Noel RJ, Putnam PE, Rothenberg ME. Eosinophilic esophagitis. N Engl J Med. 2004; 351:940-1. [PubMed: 15329438]

6. Straumann A, Simon HU. Eosinophilic esophagitis: escalating epidemiology? J Allergy Clin Immunol. 2005; 115:418-9. [PubMed: 15696105]

7. Cherian S, Smith NM, Forbes DA. Rapidly increasing prevalence of eosinophilic oesophagitis in Western Australia. Arch Dis Child. 2006; 91:1000-4. [PubMed: 16877474]

8. Ronkainen J, Talley NJ, Aro P, Storskrubb T, Johansson SE, Lind T, Bolling-Sternevald E, Vieth M, Stolte M, Walker MM, Agreus L. Prevalence of oesophageal eosinophils and eosinophilic oesophagitis in adults: The population-based Kalixanda study. Gut. 2007; 56:615-20. [PubMed: 17135307] 
9. Gill R, Durst P, Rewalt M, Elitsur Y. Eosinophilic Esophagitis Disease in Children from West Virginia: A Review of the Last Decade (1995-2004). Am J Gastroenterol. 2007; 102:2281-5. [PubMed: 17573789]

10. Buckmeier BK, Rothenberg ME, Collins MH. The incidence and prevalence of eosinophilic esophagitis. J Allergy Clin Immunol. 2008; 121(Suppl 2):S71. (AB 271).

11. Prasad GA, Alexander JA, Schleck CD, Zinsmeister AR, Smyrk TC, Elias RM, Locke GR 3rd, Talley NJ. Epidemiology of eosinophilic esophagitis over three decades in Olmsted County, Minnesota. Clin Gastroenterol Hepatol. 2009; 7:1055-61. [PubMed: 19577011]

12. Dalby K, Nielsen RG, Kruse-Andersen S, Fenger C, Bindslev-Jensen C, Ljungberg S, Larsen K, Walsted AM, Husby S. Eosinophilic Oesophagitis in Infants and Children in the Region of Southern Denmark: A Prospective Study of Prevalence and Clinical Presentation. J Pediatr Gastroenterol Nutr. 2010; 51:280-2. [PubMed: 20512060]

13. Spergel JM, Book WM, Mays E, Song L, Shah SS, Talley NJ, Bonis PA. Variation in prevalence, diagnostic criteria, and initial management options for eosinophilic gastrointestinal diseases in the United States. J Pediatr Gastroenterol Nutr. 2011; 52:300-6. [PubMed: 21057327]

14. Hruz P, Straumann A, Bussmann C, Heer P, Simon HU, Zwahlen M, Beglinger C, Schoepfer AM. Escalating incidence of eosinophilic esophagitis: A 20-year prospective, population-based study in Olten County, Switzerland. J Allergy Clin Immunol. 2011; 128:1349-1350. e5. [PubMed: 22019091]

15. Ally M, Maydonovitch C, McAllister D, Betteridge J, Moawad F, Veerappan G. The prevalence of eosinophilic esophagitis in the United States military healthcare population. Am J Gastroenterol. 2012; 107(Suppl 1):S1. (AB 2). [PubMed: 23074713]

16. Rybnicek DA, Hathorn KE, Pfaff ER, Bulsiewicz WJ, Shaheen NJ, Dellon ES. Administrative coding is specific, but not sensitive, for identifying eosinophilic esophagitis. Dis Esoph. 2013 In press.

17. Stempel DA, Mauskopf J, McLaughlin T, Yazdani C, Stanford RH. Comparison of asthma costs in patients starting fluticasone propionate compared to patients starting montelukast. Respir Med. 2001; 95:227-34. [PubMed: 11266241]

18. Kappelman MD, Rifas-Shiman SL, Kleinman K, Ollendorf D, Bousvaros A, Grand RJ, Finkelstein JA. The prevalence and geographic distribution of Crohn's disease and ulcerative colitis in the United States. Clin Gastroenterol Hepatol. 2007; 5:1424-9. [PubMed: 17904915]

19. Dellon ES, Gibbs WB, Fritchie KJ, Rubinas TC, Wilson LA, Woosley JT, Shaheen NJ. Clinical, endoscopic, and histologic findings distinguish eosinophilic esophagitis from gastroesophageal reflux disease. Clin Gastroenterol Hepatol. 2009; 7:1305-1313. [PubMed: 19733260]

20. Kim HP, Vance RB, Shaheen NJ, Dellon ES. The Prevalence and Diagnostic Utility of Endoscopic Features of Eosinophilic Esophagitis: A Meta-Analysis. Clin Gastroenterol Hepatol. 2012; 10:988-996. e5. [PubMed: 22610003]

21. Schaefer ET, Fitzgerald JF, Molleston JP, Croffie JM, Pfefferkorn MD, Corkins MR, Lim JD, Steiner SJ, Gupta SK. Comparison of oral prednisone and topical fluticasone in the treatment of eosinophilic esophagitis: a randomized trial in children. Clin Gastroenterol Hepatol. 2008; 6:16573. [PubMed: 18237866]

22. Alexander JA, Jung KW, Arora AS, Enders F, Katzka DA, Kephardt GM, Kita H, Kryzer LA, Romero Y, Smyrk TC, Talley NJ. Swallowed Fluticasone Improves Histologic but Not Symptomatic Responses of Adults with Eosinophilic Esophagitis. Clin Gastroenterol Hepatol. 2012; 10:742-9. e1. [PubMed: 22475741]

23. Dellon ES, Sheikh A, Speck O, Woodward K, Whitlow AB, Hores JM, Ivanovic M, Chau A, Woosley JT, Madanick RD, Orlando RC, Shaheen NJ. Viscous Topical is More Effective than Nebulized Steroid Therapy for Patients with Eosinophilic Esophagitis. Gastroenterology. 2012; 143:321-324. e1. [PubMed: 22561055]

24. Sperry SL, Crockett SD, Miller CB, Shaheen NJ, Dellon ES. Esophageal foreign-body impactions: epidemiology, time trends, and the impact of the increasing prevalence of eosinophilic esophagitis. Gastrointest Endosc. 2011; 74:985-91. [PubMed: 21889135] 
25. Soon IS, Butzner JD, Kaplan GG, deBruyn JCC. Incidence and prevalence of eosinophilic esophagitis in children: Systematic review and meta-analysis. J Pediatr Gastroenterol Nutr. 2013 epub March 24.

26. Liacouras CA, Spergel JM, Ruchelli E, Verma R, Mascarenhas M, Semeao E, Flick J, Kelly J, Brown-Whitehorn T, Mamula P, Markowitz JE. Eosinophilic esophagitis: a 10-year experience in 381 children. Clin Gastroenterol Hepatol. 2005; 3:1198-206. [PubMed: 16361045]

27. Prasad GA, Talley NJ, Romero Y, Arora AS, Kryzer LA, Smyrk TC, Alexander JA. Prevalence and Predictive Factors of Eosinophilic Esophagitis in Patients Presenting With Dysphagia: A Prospective Study. Am J Gastroenterol. 2007; 102:2627-32. [PubMed: 17764492]

28. Veerappan GR, Perry JL, Duncan TJ, Baker TP, Maydonovitch C, Lake JM, Wong RK, Osgard EM. Prevalence of Eosinophilic Esophagitis in an Adult Population Undergoing Upper Endoscopy: A Prospective Study. Clin Gastroenterol Hepatol. 2009; 7:420-426. [PubMed: 19162236]

29. Dellon ES, Aderoju A, Woosley JT, Sandler RS, Shaheen NJ. Variability in diagnostic criteria for eosinophilic esophagitis: A systematic review. Am J Gastroenterol. 2007; 102:2300-13. [PubMed: 17617209]

30. Gonsalves N, Policarpio-Nicolas M, Zhang Q, Rao MS, Hirano I. Histopathologic variability and endoscopic correlates in adults with eosinophilic esophagitis. Gastrointest Endosc. 2006; 64:3139. [PubMed: 16923475]

31. Assa'ad AH, Putnam PE, Collins MH, Akers RM, Jameson SC, Kirby CL, Buckmeier BK, Bullock JZ, Collier AR, Konikoff MR, Noel RJ, Guajardo JR, Rothenberg ME. Pediatric patients with eosinophilic esophagitis: an 8-year follow-up. J Allergy Clin Immunol. 2007; 119:731-8. [PubMed: 17258309]

32. Bohm ME, Richter JE. Review article: oesophageal dilation in adults with eosinophilic oesophagitis. Aliment Pharmacol Ther. 2011; 33:748-57. [PubMed: 21320137]

33. Peery AF, Shaheen NJ, Dellon ES. Practice patterns for the evaluation and treatment of eosinophilic oesophagitis. Aliment Pharmacol Ther. 2010; 32:1373-82. [PubMed: 21050240]

34. Sperry SL, Shaheen NJ, Dellon ES. Toward uniformity in the diagnosis of eosinophilic esophagitis (EoE): the effect of guidelines on variability of diagnostic criteria for EoE. Am J Gastroenterol. 2011; 106:824-32. quiz 833. [PubMed: 21304500] 


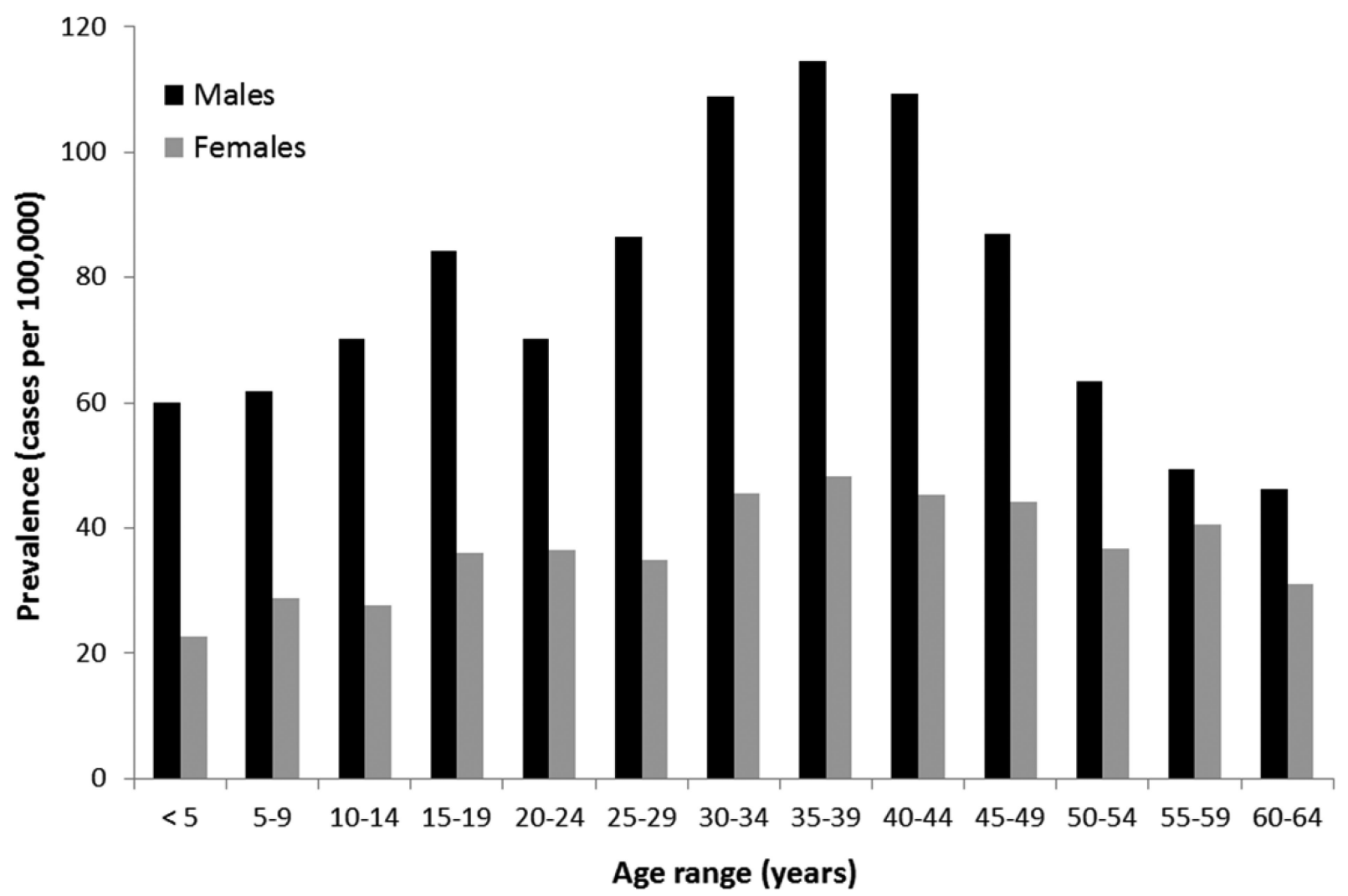

Figure 1.

Prevalence of EoE (cases per 100,000) as stratified by sex and by 5 year increments of age. Data source: IMS LifeLink® PharMetrics Health Plan Claims Database, January 2001November 2011, IMS Health Incorporated. All Rights Reserved. 


\section{Table 1}

Demographic characteristics of EoE cases

\begin{tabular}{lc}
\hline & EoE cases $^{*}(\mathbf{n}=\mathbf{1 6 , 4 0 5})$ \\
\hline Age (mean \pm SD; range) & $33.5 \pm 17.1(0-64)$ \\
$\quad$ < 18 years old $(\mathrm{n}, \%)$ & $3,933(24.0)$ \\
Male (n, \%) & $10,650(64.9)$ \\
Number of 530.13 claims per person (mean \pm SD; range) & $7.4 \pm 11.0 ; 1-335$ \\
Region of country & \\
East & $3,125(19.1)$ \\
Midwest & $5,512(33.6)$ \\
South & $5,270(32.1)$ \\
West & $2,498(15.2)$ \\
Number of unique cases per year & \\
2008 & $1227(7.5)$ \\
2009 & $5460(33.3)$ \\
2010 & $5270(32.1)$ \\
2011 & $4448(27.1)$ \\
\hline
\end{tabular}

Data source: IMS LifeLink® PharMetrics Health Plan Claims Database, January 2001-November 2011, IMS Health Incorporated. All Rights Reserved.

Patients with at least one or more instance of an ICD-9 claim for 530.13 between 2008-2011 
Table 2

Clinical features of EoE cases

\begin{tabular}{|c|c|}
\hline & EoE cases ${ }^{*}(n=16,405)$ \\
\hline \multicolumn{2}{|l|}{ Symptoms and diagnoses $(\mathrm{n}, \%)$} \\
\hline Dysphagia & $9,147(55.8)$ \\
\hline Esophageal foreign body & $2,043(12.5)$ \\
\hline Esophageal stricture & $4,709(28.7)$ \\
\hline Esophageal web/congenital stenosis & $846(5.2)$ \\
\hline Esophageal perforation & $67(0.4)$ \\
\hline Abdominal pain/dyspepsia & $7,686(46.9)$ \\
\hline Heartburn & $1,448(8.8)$ \\
\hline Pain in chest or throat & $4,669(28.4)$ \\
\hline Nausea or vomiting & $4,253(25.9)$ \\
\hline Failure to thrive & $516(3.1)$ \\
\hline \multicolumn{2}{|l|}{ Allergic diseases (n, \%) } \\
\hline Any allergic disease & $8,663(52.8)$ \\
\hline Rhinitis & $6,850(41.8)$ \\
\hline Sinusitis & $2,493(15.2)$ \\
\hline Dermatitis & $1,418(8.6)$ \\
\hline Urticaria & $297(1.8)$ \\
\hline Asthma & $3841(23.4)$ \\
\hline Food allergies & $771(4.7)$ \\
\hline \multicolumn{2}{|l|}{ Medications (n, \%) ${ }^{\dagger}$} \\
\hline $\mathrm{H} 2$ receptor blockers & $459(3.7)$ \\
\hline Proton-pump inhibitors & $6,467(52.2)$ \\
\hline Systemic corticosteroids & $3,498(28.2)$ \\
\hline Steroid preparation that could be used topically ${ }^{t}$ & $1,431(11.5)$ \\
\hline Anti-histamines $^{\#}$ & $1,300(10.5)$ \\
\hline Leukotriene antagonists $^{* *}$ & $1,488(12.0)$ \\
\hline
\end{tabular}

Data source: IMS LifeLink@ PharMetrics Health Plan Claims Database, January 2001-November 2011, IMS Health Incorporated. All Rights Reserved.

Patients with at least one or more instance of an ICD-9 claim for 530.13 between 2008-2011

${ }^{\dagger}$ Medication data derived from 12,390 EoE subjects with a pharmacy drug benefit

* The asthma or nasal preparations of fluticasone, budesonide, beclomethasone, mometasone, ciclesonide, or flunisolide

\# Loratadine, desloratadine, fexofenadine, cetirizine, or levocetirizine

** Montelukast, zafirlukast, or zileuton

Clin Gastroenterol Hepatol. Author manuscript; available in PMC 2015 April 01. 
Table 3

Features of adults vs children with EoE:

\begin{tabular}{|c|c|c|}
\hline & Children $^{\dagger, *}(\mathrm{n}=\mathbf{3 , 9 3 3 )}$ & Adults ${ }^{*}(\mathrm{n}=12,472)$ \\
\hline Age $($ mean \pm SD; range $)$ & $10.1 \pm 5.0(0-17)$ & $40.9 \pm 12.1(18-64)$ \\
\hline Male (n, \%) & $2,755(70.1)$ & $7,895(63.3)$ \\
\hline \multicolumn{3}{|l|}{ Region of country } \\
\hline East & $888(22.6)$ & $2,237(17.9)$ \\
\hline Midwest & $1,219(31.0)$ & $4293(34.4)$ \\
\hline South & $1,392(35.4)$ & $3,878(31.1)$ \\
\hline West & $434(11.0)$ & $2,064(16.6)$ \\
\hline \multicolumn{3}{|l|}{ Symptoms and diagnoses $(\mathrm{n}, \%)$} \\
\hline Dysphagia & $1,261(32.1)$ & $7,886(63.2)$ \\
\hline Esophageal foreign body & $270(6.9)$ & $2,043(12.5)$ \\
\hline Esophageal stricture & $218(5.5)$ & $4,491(36.0)$ \\
\hline Esophageal web/congenital stenosis & $25(0.6)$ & $821(6.6)$ \\
\hline Esophageal perforation & $4(0.1)$ & $63(0.5)$ \\
\hline Abdominal pain/dyspepsia & $2,236(56.9)$ & $5,450(43.7)$ \\
\hline Heartburn & $144(3.7)$ & $1,304(10.5)$ \\
\hline Pain in chest or throat & $682(17.3)$ & $3,987(32.0)$ \\
\hline Nausea or vomiting & $1,679(42.7)$ & $4,253(25.9)$ \\
\hline Failure to thrive & $465(11.8)$ & $51(0.4)$ \\
\hline \multicolumn{3}{|l|}{ Allergic diseases (n, \%) } \\
\hline Any allergic disease & $2,578(65.6)$ & $6,085(48.8)$ \\
\hline Rhinitis & $2,135(54.3)$ & $4,715(37.8)$ \\
\hline Sinusitis & $567(14.4)$ & $1,926(15.4)$ \\
\hline Dermatitis & $669(17.0)$ & $749(6.0)$ \\
\hline Urticaria & $126(3.2)$ & $171(1.4)$ \\
\hline Asthma & $1,481(37.7)$ & $2,360(18.9)$ \\
\hline Food allergies & $387(9.8)$ & $384(3.1)$ \\
\hline \multicolumn{3}{|l|}{ Medications (n, \%) } \\
\hline $\mathrm{H} 2$ receptor blockers & $206(7.1)$ & $253(2.7)$ \\
\hline Proton-pump inhibitors & $1,589(54.8)$ & $4,878(51.4)$ \\
\hline Systemic corticosteroids & $539(18.6)$ & $2,959(31.2)$ \\
\hline Steroid preparation that could be used topically & $630(21.7)$ & $801(8.4)$ \\
\hline Anti-histamines $^{* *}$ & $473(16.3)$ & 827 (8.7) \\
\hline Leukotriene antagonists $^{\dagger \dagger}$ & $665(22.9)$ & $823(8.7)$ \\
\hline
\end{tabular}

Analyses in this table are for patients with at least one or more instance of an ICD-9 claim for 530.13 between 2008-2011

Data source: IMS LifeLink® PharMetrics Health Plan Claims Database, January 2001-November 2011, IMS Health Incorporated. All Rights Reserved.

${ }^{\dagger}$ Children defined as $<18$ years of age.

For comparisons between adults and children, $\mathrm{p}<0.001$ for all rows except for sinusitis $(\mathrm{p}=0.12)$ 
\# Medication data derived from 12,390 EoE subjects (2,900 children and 9,490 adults) with a pharmacy drug benefit

\# The asthma or nasal preparations of fluticasone, budesonide, beclomethasone, mometasone, ciclesonide, or flunisolide **

Loratadine, desloratadine, fexofenadine, cetirizine, or levocetirizine

${ }^{\dagger \dagger}$ Montelukast, zafirlukast, or zileuton 
Table 4

Prevalence of EoE in the study database ${ }^{*}$

\begin{tabular}{|c|c|c|c|c|c|}
\hline & \multirow[b]{2}{*}{ Source population } & \multicolumn{2}{|c|}{$\begin{array}{l}\text { Primary EoE case definition (at least one } \\
530.13 \text { code) }\end{array}$} & \multicolumn{2}{|c|}{$\begin{array}{c}\text { Restrictive EoE case definition (>1 code }+ \\
\text { exclusions) }\end{array}$} \\
\hline & & $\underset{(\%)}{\operatorname{EoE} \text { cases n }}$ & Prevalence (per 100,000) & $\begin{array}{l}\text { EoE cases n } \\
\quad(\%)\end{array}$ & Prevalence (per 100,000) \\
\hline \multicolumn{6}{|l|}{ Age group } \\
\hline$<20^{\dagger}$ & $3,587,571$ & $1,813(27.8)$ & 50.5 & $1,348(29.9)$ & 37.6 \\
\hline $20-64$ & $7,981,646$ & $4,700(72.2)$ & 58.9 & $3,167(70.1)$ & 39.7 \\
\hline \multicolumn{6}{|l|}{ Sex } \\
\hline Male & $5,544,574$ & $4,257(65.4)$ & 76.8 & $2,978(66.0)$ & 65.9 \\
\hline Female & $6,024,643$ & $2,256(34.6)$ & 37.4 & $1,537(34.0)$ & 34.0 \\
\hline \multicolumn{6}{|l|}{ Region } \\
\hline East & $2,226,470$ & $1,054(16.2)$ & 47.3 & $715(15.8)$ & 32.1 \\
\hline South & $4,529,151$ & $2,507(38.5)$ & 55.4 & $1,739(38.5)$ & 38.4 \\
\hline Midwest & $3,569,432$ & $2,567(39.4)$ & 71.9 & $1,809(40.1)$ & 50.7 \\
\hline West & $1,244,164$ & $385(5.9)$ & 30.9 & $252(5.6)$ & 20.3 \\
\hline Overall prevalence & $11,569,217$ & $6,513(100)$ & 56.3 & $4,515(100)$ & 39.0 \\
\hline \multicolumn{6}{|c|}{$\begin{array}{l}\text { Data source: IMS LifeLink® PharMetrics Health Plan Claims Database, January 2001-November 2011, IMS Health Incorporated. All Rights } \\
\text { Reserved. }\end{array}$} \\
\hline
\end{tabular}


Table 5

Estimates of the prevalence of EoE in the medical literature

\begin{tabular}{|c|c|c|c|c|c|c|c|}
\hline Author, year & Location & Study type, population & Population age & N (Population) & $\mathbf{N}(\mathbf{E o E})$ & Time of estimate & $\begin{array}{c}\text { Prevalence } \\
\text { estimate } \\
\text { (per } \\
\text { 100,000) }\end{array}$ \\
\hline Noel, 2004 & Hamilton $\mathrm{Co}, \mathrm{OH}$ & $\begin{array}{l}\text { Single center, retrospective, } \\
\text { pediatric }\end{array}$ & Pediatric & -- & 103 & $2000-2003$ & 43.0 \\
\hline Cherian, 2006 & Perth, Australia & $\begin{array}{l}\text { Single center, retrospective, } \\
\text { pediatric }\end{array}$ & Pediatric & -- & 285 & 1995, 1999, 2004 & 89.0 \\
\hline Gill, 2007 & Huntington region, WV & $\begin{array}{l}\text { Single center, retrospective, } \\
\text { pediatric }\end{array}$ & Pediatric & $\sim 600,000$ & 44 & 1995-2004 & 73.0 \\
\hline Buckmeier, 2008 & Hamilton $\mathrm{Co}, \mathrm{OH}$ & $\begin{array}{l}\text { Single center, retrospective; } \\
\text { pediatric }\end{array}$ & Pediatric & -- & -- & 2000-2006 & 90.7 \\
\hline Dalby, 2010 & Southern Denmark & Multicenter, prospective; pediatric & Pediatric & 256,164 & 6 & 2005-2007 & 2.3 \\
\hline Straumann, 2005 & Olten Co, Switzerland & Single center, retrospective, adult & Adult & $\sim 100,000$ & 23 & 1989-2004 & 23.0 \\
\hline Ronkainen, 2006 & Northern Sweden & Population-based, prospective, adult & Adult & 1,000 & 4 & 1998-2001 & 400 \\
\hline Hruz, 2012 & Olten County, Switzerland & Single center, retrospective, adult & Adult & $\sim 90,000$ & 39 & 1989-2009 & 42.8 \\
\hline Spergel, 2011 & U.S. & Physician survey & -- & 1,863 MDs & -- & 2010 & 52.2 \\
\hline Prasad, 2009 & Omstead Co, MN & $\begin{array}{c}\text { Population-based, retrospective, all } \\
\text { ages }\end{array}$ & Pediatric and adult & $\sim 140,000$ & 78 & 1976-2005 & 55.0 \\
\hline Ally, 2012 & U.S. (Military) & Administrative data; all ages & Pediatric and adult & $10,180,515$ & 987 & 2009 & 9.7 \\
\hline Present study ${ }^{*}$ & U.S. & Administrative data; all ages & Pediatric and adult & $11,569,217$ & 6,513 & 2009-2011 & 56.7 \\
\hline
\end{tabular}

